\title{
An experimental study on steel and Teflon squeeze film dampers
}

\author{
Asad A. Khalid ${ }^{\mathrm{a}}$, A. Albagul ${ }^{\mathrm{b}}$, W. Faris ${ }^{\mathrm{a}}$ and Godem A. Ismail ${ }^{\mathrm{b}}$ \\ ${ }^{a}$ Mechanical Engineering Department, International Islamic University Malaysia, Jalan Gombak, 53100, KL, \\ Malaysia \\ E-mail: asad@iiu.edu.my \\ ${ }^{\mathrm{b}}$ Mechatronics Engineering Department, International Islamic University Malaysia, Jalan Gombak, 53100, KL, \\ Malaysia \\ E-mail: albagul@iiu.edu.my
}

Received 24 April 2005

\begin{abstract}
In this paper, the vibration analysis on Teflon and steel squeeze film dampers has been carried out. At different frequency ranges, vibration amplitude and the resonance frequency are measured. The eccentricity ratio at resonance speed has been determined. Results show that the vibration amplitude of the steel damper is $10 \%$ less at resonance compared with the Teflon damper. On the other hand, saving weight of $36 \%$ has been achieved by using the Teflon damper.

A rotor bearing system for vibration analysis has been designed and fabricated. The test rig consists of mild steel shaft with two supports, oil pressure gauge system and two self-alignment ball bearings fixed on each end support. Two squeeze film dampers are used at each of the rotor support ends. Teflon and steel squeeze film dampers (SFD) were fabricated and tested using turning machine.
\end{abstract}

Keywords: Squeeze film dampers, bearings, vibration

\section{Introduction}

Squeeze film dampers have been used successfully in many applications as aircraft jet engines, turbo machines and commercial compressors, to increase damping, increase the range of rotating speed and reduce vibration levels. The trend in turbo-machinery design for increase operating speed and power to weight ratio has lead to lighter and more flexible rotor bearing system. Squeeze Film Dampers (SFDs) is widely used in high speed turbo-machinery due to their capability to attenuate the amplitude of rotor vibrations and to decrease the forces transmitted to the structure. In addition the energy dissipated by viscous dampers contributes to improve the dynamics stability characteristics of this rotor bearing systems.

Computational fluid dynamics has been used to study the influence of end seal clearance and flow path length on the performance of a circular orbiting squeeze film dampers with a central circumferential feed groove [5]. Results indicate that to be effective in modifying the dampers stiffness and damping characteristics, the axial clearance between the damper and the seal need to be close to a II-film, regardless of the seal clearances and oil flow pattern are also given. A rotor made of magnetic powder contained epoxy for high speed built in type spindle motor system was designed, manufactured and studied by [3]. They found that the composite rotor had several advantage such as slow slip, less power consumption with mass reduction of $41 \%$ compared to those of conventional silicon steel rotors. In 1999, Tan et al. [9] studied the effect of the feeding groove of unbalance response of flexible rotor in SFD. Fluid forces in squeeze film dampers with a circumferential feeding groove have been studied by Tan et al. [10]. The effect or arrangement and oil supply pressure on the performance of a squeeze film damper have been studied by Holmes et al. [6]. The effect of circumferential feeding groove on the dynamic force response of a seal squeeze film damper 


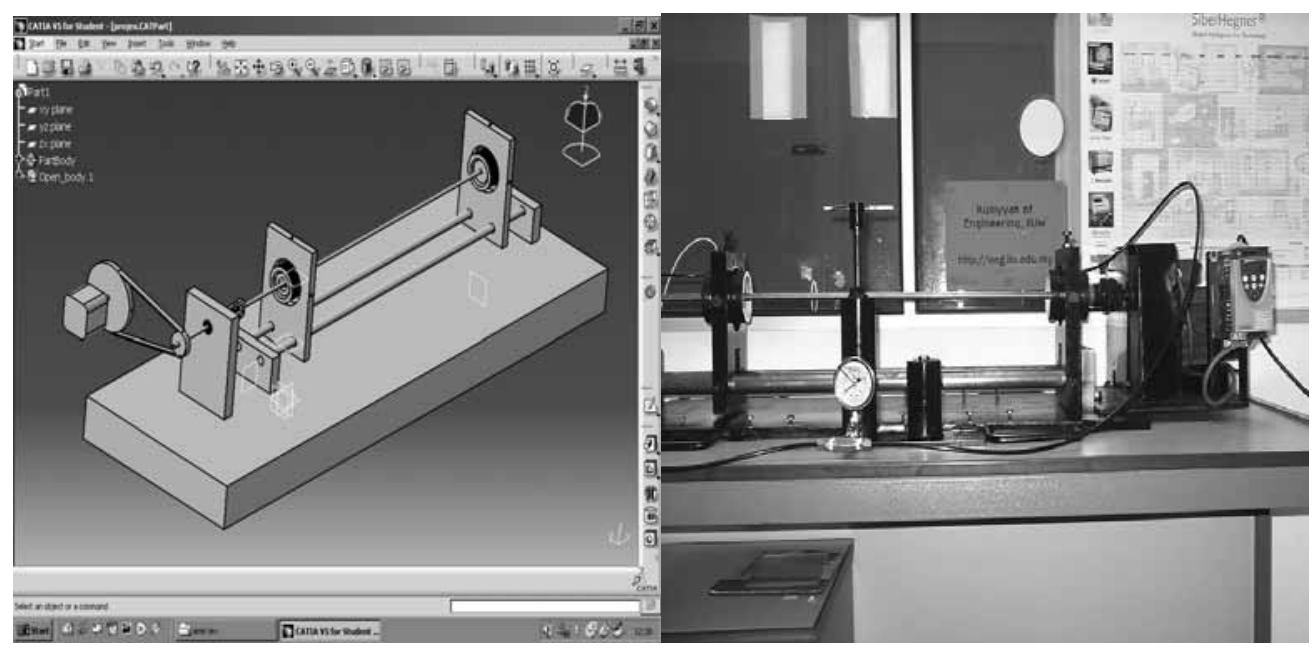

(a)

(b)

Fig. 1. The test rig

is studied experimentally by Arauz et al. [2]. In 1994, the effect of supply pressure and end seals has been studied by Holmes et al. [7]. Results of the study has been compared with the theoretical results and compared with the predictions based on the harmonic balance principle. Andress [1] studied the dynamics of flow interactions between feeding groove volumes and the squeeze film dampers. His analysis considers for simplicity a short open-end SFD model configuration and it restricts attention to small amplitude motion about the centered position. In most aero-engine applications, the purpose of squeeze-film is to introduce damping as a series element between the outer race of a rolling element bearing and its rather flexible housing, so that the rotor can safely negotiate any critical speeds and operate smoothly at higher speeds [8]. An automotive hybrid aluminum composite drive shaft has been designed and manufactured by Lee et al. [?]. They concluded that the development of one-piece automotive hybrid aluminum composite drive shaft had $75 \%$ mass reduction and $160 \%$ increase in torque capability compared with a conventional two piece steel drive shaft. Also, it had $9390 \mathrm{rpm}$ of natural frequency which was higher than the design specification of $9200 \mathrm{rpm}$. The main objectives of this present study are to Design and fabricate a rotor bearing system in a form that enables changing bearing easily for both of research and maintenance purpose. Also to investigate the effect of using Teflon and mild steel squeeze film dampers on the vibration response of the rotor bearing system. Vibration amplitude, eccentricity ratio and the 1st resonance frequency are to be examined and compared for both of the fabricated dampers.

\section{Experimental setup}

\subsection{Test rig design and fabrication}

The test rig for vibration analysis of a squeeze film damper has been designed and fabricated. CATIA software has been used to design a model for the test rig as shown in Fig. 1(a). The fabricated test rig is shown in Fig. 1(b). A schematic diagram of the designed test rig is shown in Fig. 2. It consists of an Electric motor (1) with speed controller to provide the required rotational speed, two pulleys (2) with v-belt and at a speed ratio of 1:4 that could easily increase the test shaft speed to $10,000 \mathrm{rpm}$. A flexible coupling (4) was used to transmit the motion to the test rig shaft. The test rig shaft was of $0.8 \mathrm{~m}$ length and supported by two bearing supports (6) which assembled together with the bearing case (7), squeeze film dampers (8) and self-alignment ball bearing (9). Three types of squeeze film dampers were tested. They are made of steel, rubber and composite materials respectively. All the test rig parts assembled are supported by base (11) and general support (12). Vibration response was taken by two transducers (13) connected to the bearing case in $\mathrm{X}$ and $\mathrm{Y}$ directions. The response is sent to the data acquisition system (14) and be analyzed by the DASY LAB software. 


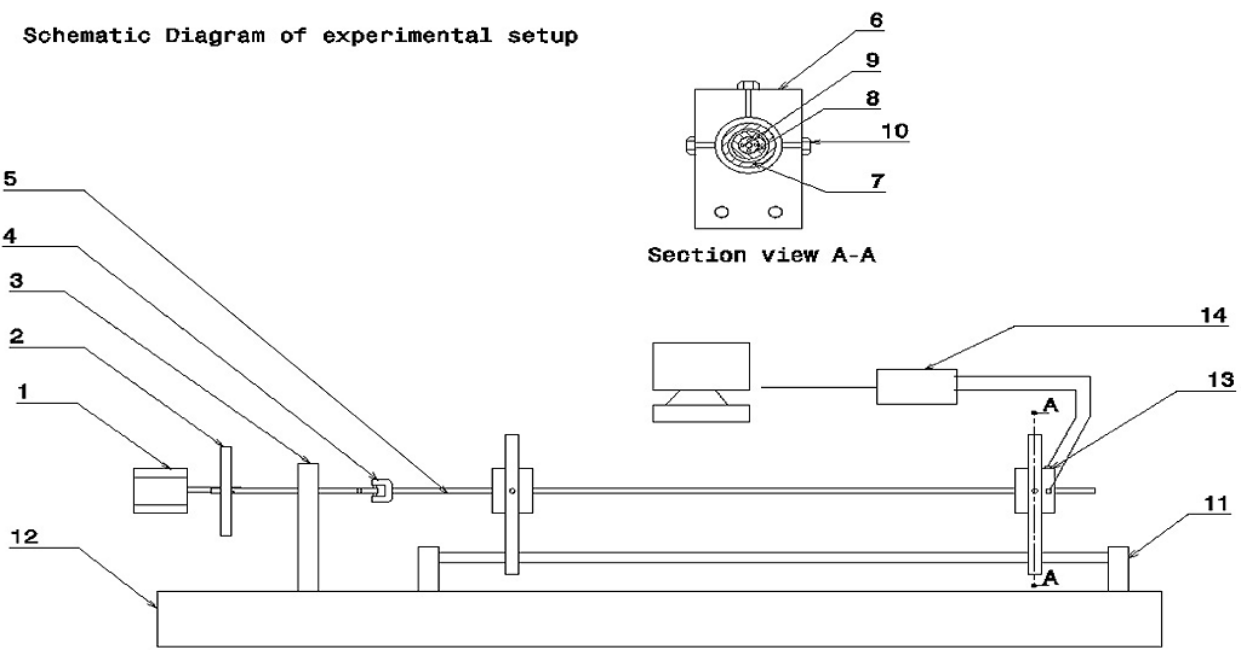

Fig. 2. Schematic diagram of the test rig.

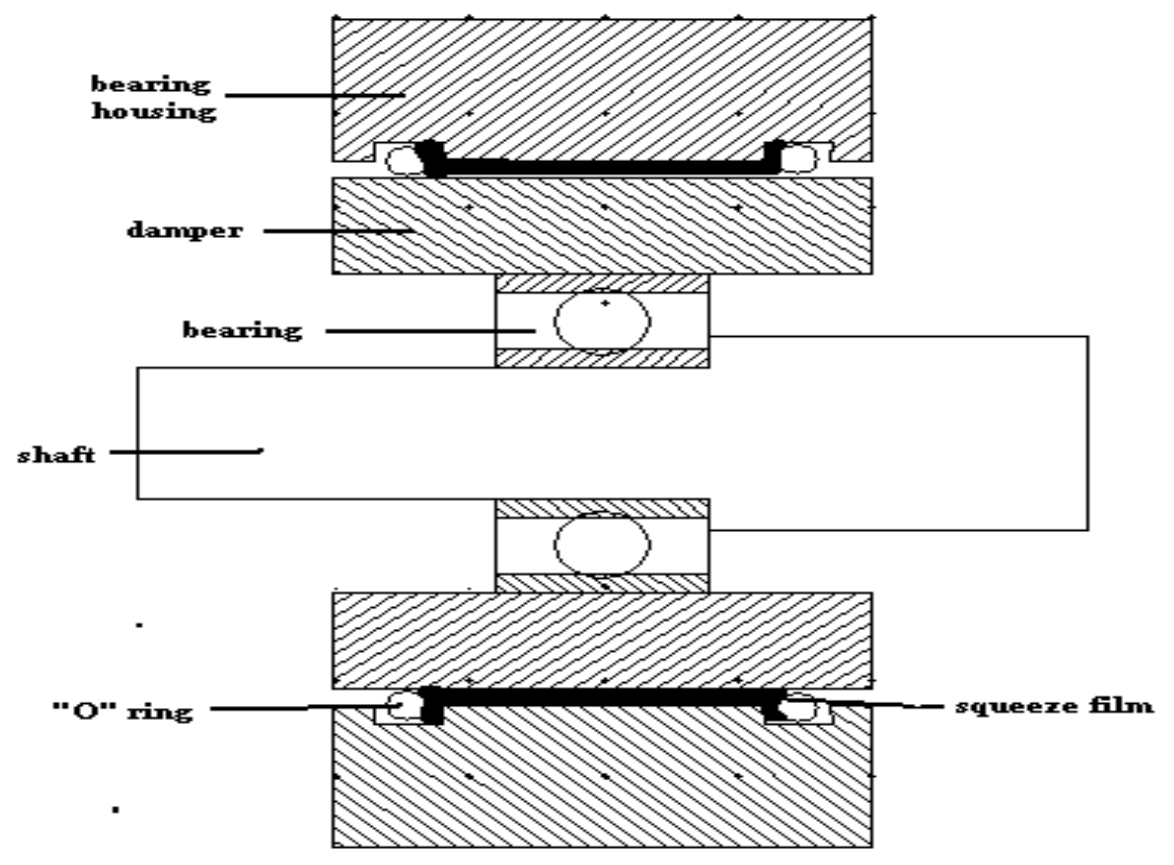

Fig. 3. Schematic diagram of the squeeze film damper bearing.

\subsection{Dampers fabrication}

Figure 3 shows a schematic diagram of the squeeze film damper. Steel and Teflon dampers were fabricated using turning machine. Samples of the fabricated dampers are shown in Fig. 4. Two "O" rings seals were used for each damper to provide the required damper length and to prevent the oil from coming out from the damper surface.

\subsection{Oil pressure system fabrication}

An oil pressure system was designed and fabricated to supply the required oil pressure to the squeeze film damper. Three pressure values of 1,2 and 3 bar were considered to examine the oil pressure effect on vibration response of 


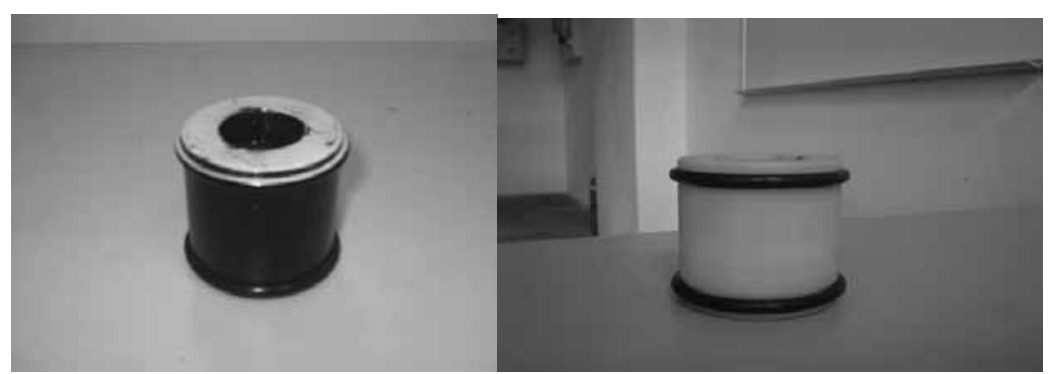

Fig. 4. Sample of the fabricated steel and Teflon dampers.

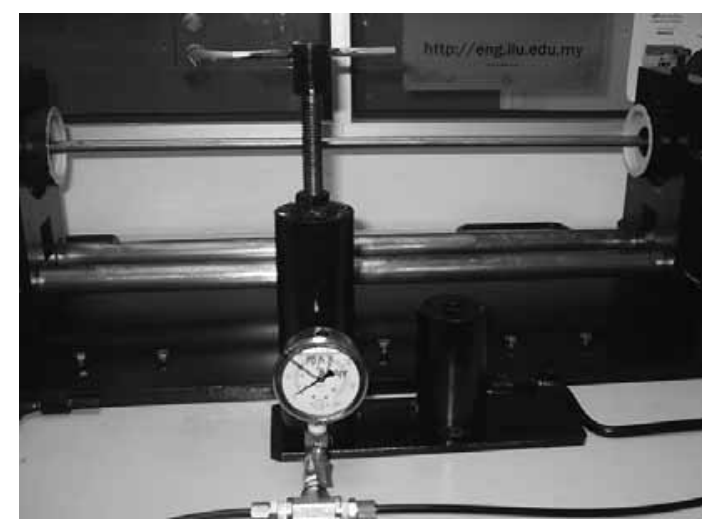

Fig. 5. Oil pressure system.

the tested dampers. The oil pressure system consists of one oil reservoir, oil pressure chamber with pressure piston, oil tubing and manual handle system to control the oil pressure. Besides that one pressure gauge meter to monitor the pressure of the oil.

\section{Experimental results}

\subsection{Natural frequency of the shaft}

The natural frequency of the shaft has been determined for the simply supported shaft using the following Equation:

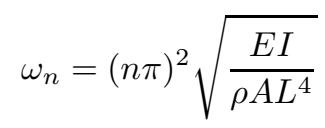

Where,

$n$ is the mode number, ( 1 for the first mode);

$\omega_{n}$ is the natural frequency of the shaft $(\mathrm{rad} / \mathrm{s})$.

The following specifications have been used to calculate the natural frequency for the test shaft.

$L s=0.724 \mathrm{~m}, D s=0.0121 \mathrm{~m}, E=207 \times 10^{9} \mathrm{~N} / \mathrm{m}, \rho=7840 \mathrm{~kg} / \mathrm{m}^{3}, A_{s}=\pi / 4(0.0121)^{2}=1.150 \times 10^{-4} \mathrm{~m}^{2}$, $I=\pi(0.0121)^{2} / 64=1.05 \times 10^{-9} \mathrm{~m}^{2}$.

$$
\omega_{n}=(\pi)^{2} \sqrt{\begin{array}{c}
\left(207 \times 10^{9}\right) \times\left(1.05 \times 10^{-9}\right) \\
(7840) \times\left(1.15 \times 10^{-4}\right) \times(0.724)^{4}
\end{array}}=292.57 \mathrm{rad} / \mathrm{sec}=2793.1 \mathrm{rpm}
$$

Figure 6 shows the vibration amplitude of the fabricated simply supported shaft. The response was taken in $x$ and $y$ directions. As shown from this Figure, displacement in $y$ direction is higher than that in the $x$ direction at all the test shaft rotational speeds. Experimentally, the resonance frequency of the shaft was found to be $2703 \mathrm{rpm}$. The fabricated test rig percentage error was found to be $3.2 \%$. 


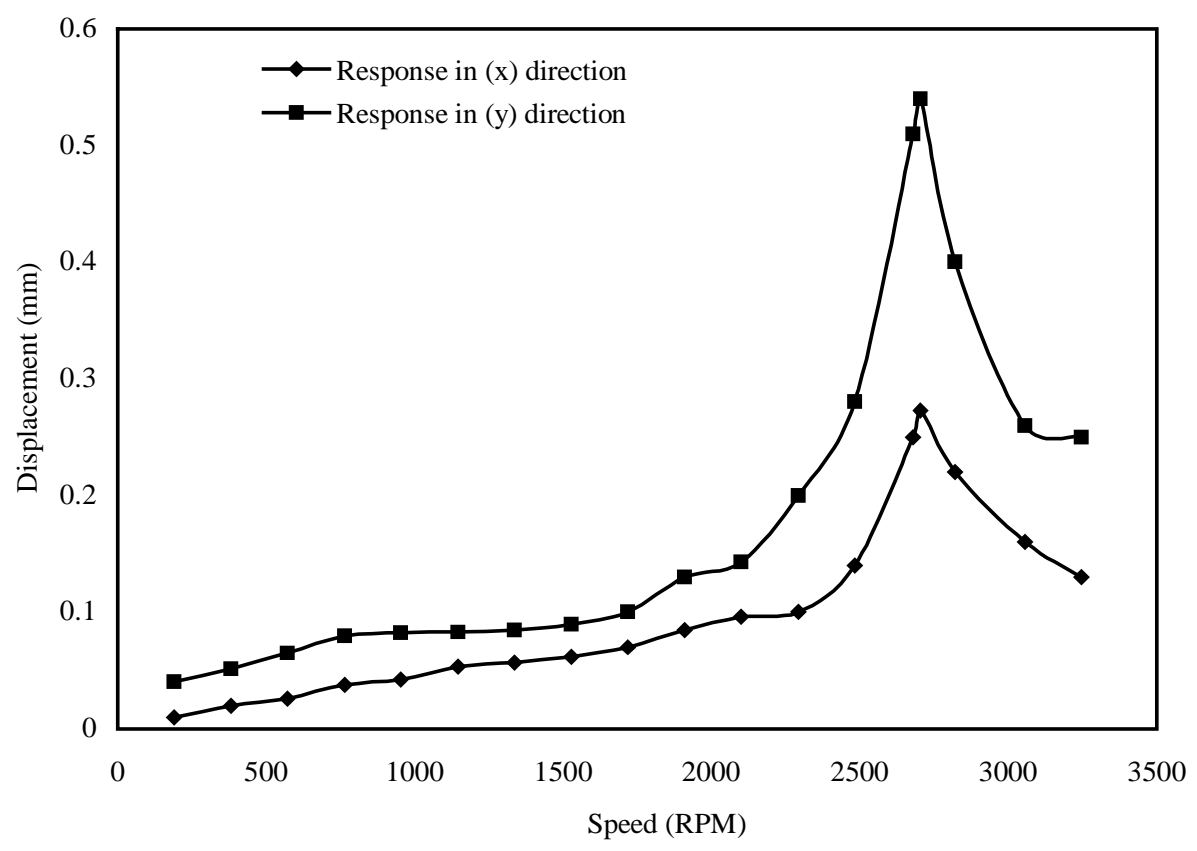

Fig. 6. Speed - displacement relation for simply supported shaft (Mild steel shaft of $0.724 \mathrm{~m}$ length).

\subsection{Steel damper}

The effect of oil pressure on the vibration response of steel squeeze film damper is shown in Fig. 7. The eccentricity ratio (e/c) was calculated by the following Equation:

$$
{ }_{c}^{e}={ }_{c}^{\delta}=\frac{\sqrt{ } \delta x^{2}+\delta y^{2}}{c}
$$

Where $e=\delta$ is the eccentricity and $\mathrm{c}$ is the oil film clearance.

As shown in Fig. 7, with increasing the oil pressure from 1 bar to 3 bars, the eccentricity ratio and the vibration amplitude decreased. The vibration amplitude at resonance decreased about $13 \%$.

\subsection{Teflon damper}

Figure 8 shows the shaft speed with eccentricity ratio in relation for Teflon damper. As shown from this Figure similar to steel damper, the eccentricity ratio and vibration amplitude decreased with increasing the oil film pressure to tested range of (1 to 3 ) bar. The amplitude at resonance decreased $16 \%$.

\subsection{Comparison}

In this section, the resonance frequency and the eccentricity ratio at resonance have been compared for both of Teflon and steel dampers. Figure 9 shows that the 1st resonance for steel damper occurs at higher levels than Teflon damper. A maximum percentage difference of $20 \%$ was found at oil pressure of 3 bars.

Figure 10 shows the effect of oil pressure on the vibration amplitude at resonance for both of steel and Teflon dampers. As shown from this Figure, with increasing oil pressure, the vibration amplitude decreased. On the other hand the percentage difference decreasing between the two dampers with increasing oil pressure to 3 bars.

Table 1 shows the results of the tested Teflon and steel dampers. A weight decrease of $20 \%$ was achieved with using the Teflon damper compared with the steel damper. 


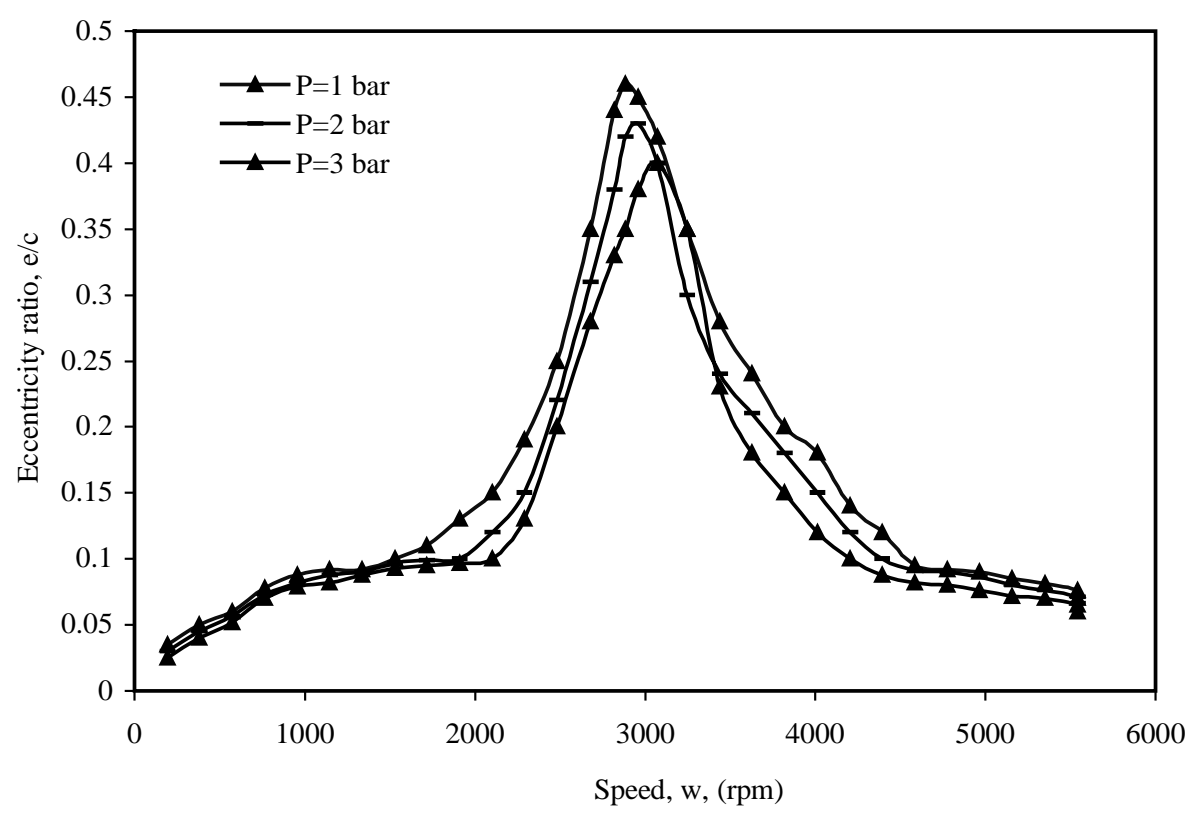

Fig. 7. Speed - eccentricity ratio relation for steel squeeze film damper $(\mathrm{L} / \mathrm{d}=0.93, \mathrm{c}=0.9)$.

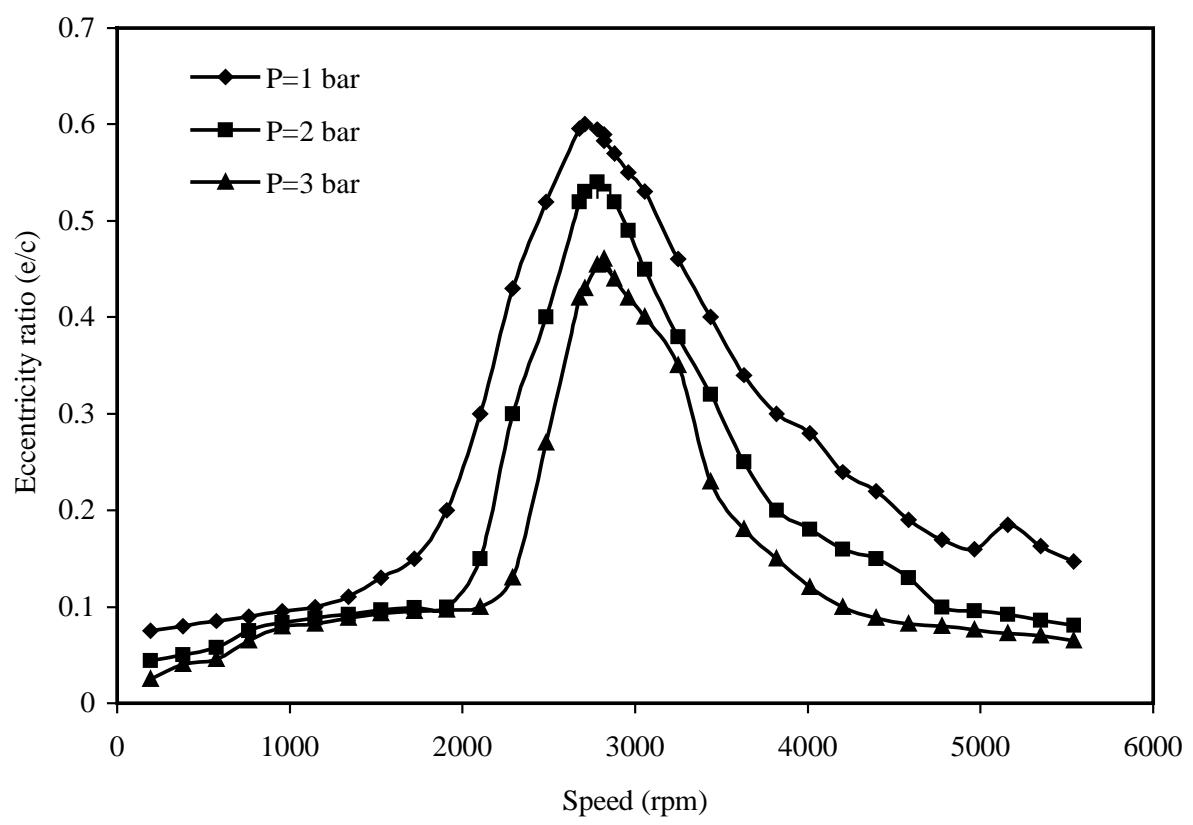

Fig. 8. Speed - eccentricity ratio relation for Teflon squeeze film damper $(\mathrm{L} / \mathrm{d}=0.96, \mathrm{C}=0.88)$.

\section{Discussion and conclusion}

The test rig and dampers have been designed and fabricated carefully. Three tests were done for each damper and at each oil pressure condition of the fabricated squeeze film dampers in order to get better results consistency. Rotational speed at resonance frequency was found to be 2703 with an acceptable error of $3.2 \%$. It has been noticed that, for both steel and Teflon dampers, the vibration response in $y$-direction was higher than in $x$ direction. Results 


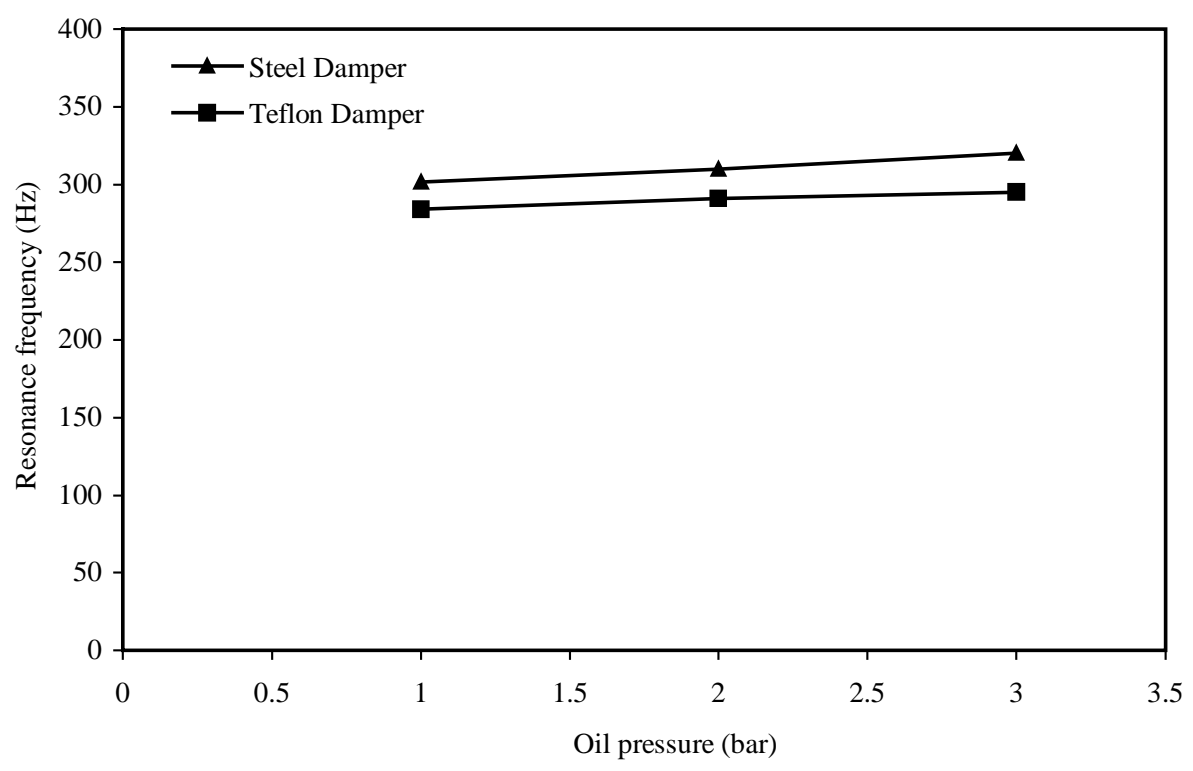

Fig. 9. Oil pressure effect on resonance frequency for steel and Teflon dampers.

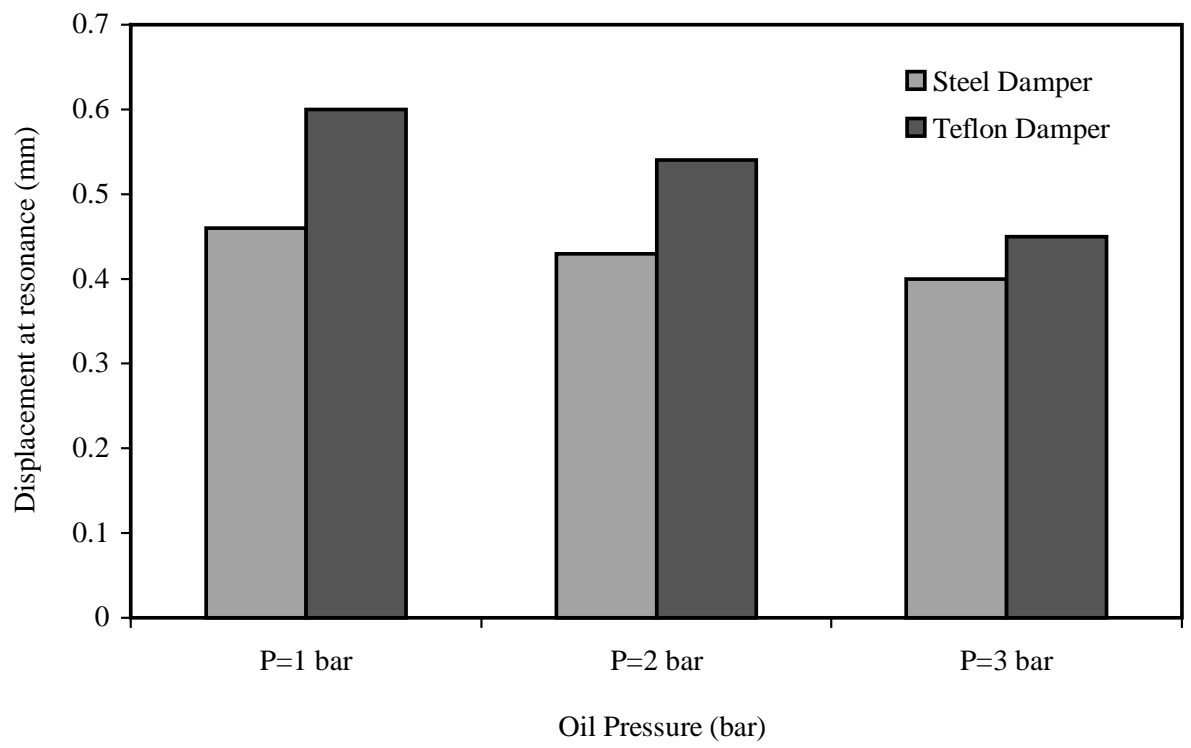

Fig. 10. Oil pressure effect on Displacement at resonance.

show that, with increasing oil pressure for the range tested, the vibration amplitude improved $13 \%$ for steel damper and $16 \%$ for the Teflon damper. The resonance frequency level of steel and Teflon dampers have been increased $6.02 \%$ and $3.91 \%$ respectively with increasing the oil pressure from 1 to 3 bars. The maximum amplitude at first resonance frequency was $0.46 \mathrm{~mm}$ for steel damper and $0.602 \mathrm{~mm}$ for Teflon damper. Teflon damper was $36 \%$ less in weight than the Steel damper. Furthermore, a percentage difference of $8 \%$ resonance frequency and $20 \%$ vibration amplitude at 3 bar oil pressure were found between the two tested dampers. 
Table 1

Results of dampers speed and amplitude at resonance

\begin{tabular}{|c|c|c|c|c|c|c|c|}
\hline \multirow[t]{3}{*}{ No } & \multirow[t]{3}{*}{ Material } & \multirow{3}{*}{$\begin{array}{l}\text { Pressure } \\
\text { P, bar }\end{array}$} & \multirow{3}{*}{$\begin{array}{c}\text { Speed at } \\
\text { Resonance } \\
\omega_{n}(\mathrm{rpm})\end{array}$} & \multirow{3}{*}{$\begin{array}{c}\text { Amplitude at } \\
\text { resonance } \\
\delta(\mathrm{mm})\end{array}$} & \multicolumn{3}{|c|}{ Damper parameters } \\
\hline & & & & & Length (mm) & Outer diameter $(\mathrm{mm})$ & Dampers weight $(\mathrm{kg})$ \\
\hline & & & & & & & \\
\hline \multirow[t]{3}{*}{1} & Steel & 1 & 2885 & 0.46 & 55 & 60 & 0.16 \\
\hline & & 2 & 2960 & 0.43 & 55 & 60 & 0.16 \\
\hline & & 3 & 3070 & 0.4 & 55 & 60 & 0.16 \\
\hline \multirow[t]{3}{*}{2} & Teflon & 1 & 2710 & 0.602 & 55 & 60 & 0.25 \\
\hline & & 2 & 2780 & 0.540 & 55 & 60 & 0.25 \\
\hline & & 3 & 2820 & 0.501 & 55 & 60 & 0.25 \\
\hline
\end{tabular}

\section{References}

[1] L.S. Andress, Analysis of short squeeze film damper with a central groove, Journal of Tribology 114 (1992), 659-665.

[2] G.L. Arauz and L.S. Andress, Experimental study on the effect of a circumferential feeding groove in the dynamics force response of a sealed squeeze film damper, Transaction of the ASME 118 (1995), 900-905.

[3] S.H. Chan, G.L. Dai and K.C. Jin, Composite rotor for high-speed induction motors, Composite Structure 50 (2000), 37-47.

[4] G.L. Dai, S.K. Hak, W.K. Jong and K.K. Jin, Design and manufacture of an automotive hybrid aluminum composite drive shaft, Composite Structures 63 (2004), 87-99.

[5] E.J. Hahn and P.Y.P. Chen, Side clearance effects on squeeze film damper performance, Tribology International 33 (2000), 161-165.

[6] R. Holmes and M.C. Levesly, The effect of oil supply and sealing arrangements on fluid force in short squeeze film dampers an Experimental study, Proceedings of the Institution of Engineers 210 (1996), 221-232.

[7] R. Holmes and M.C. Levesly, Experimental investigation into the vibration response on an aero engine rotor-damper assembly, Proceedings of the Mechanical Engineers 118 (1994), 52-66.

[8] R. Holmes and M. Dogan, The performance of a sealed squeeze film bearing in flexible support structure, Proc. Institution of Mechanical Engineers 199 (1994), 1-9.

[9] Q. Tan and X. Li, Analytical study on effect of a circumferential feeding groove on unbalance response of a flexible rotor in squeeze film damper, Tribology International 32 (1999), 559-566.

[10] O. Tan, Y. Chang and L. Wang, Effect of circumferential feeding groove on the fluid force in short squeeze film dampers, Tribology International 30 (1997), 409-416. 

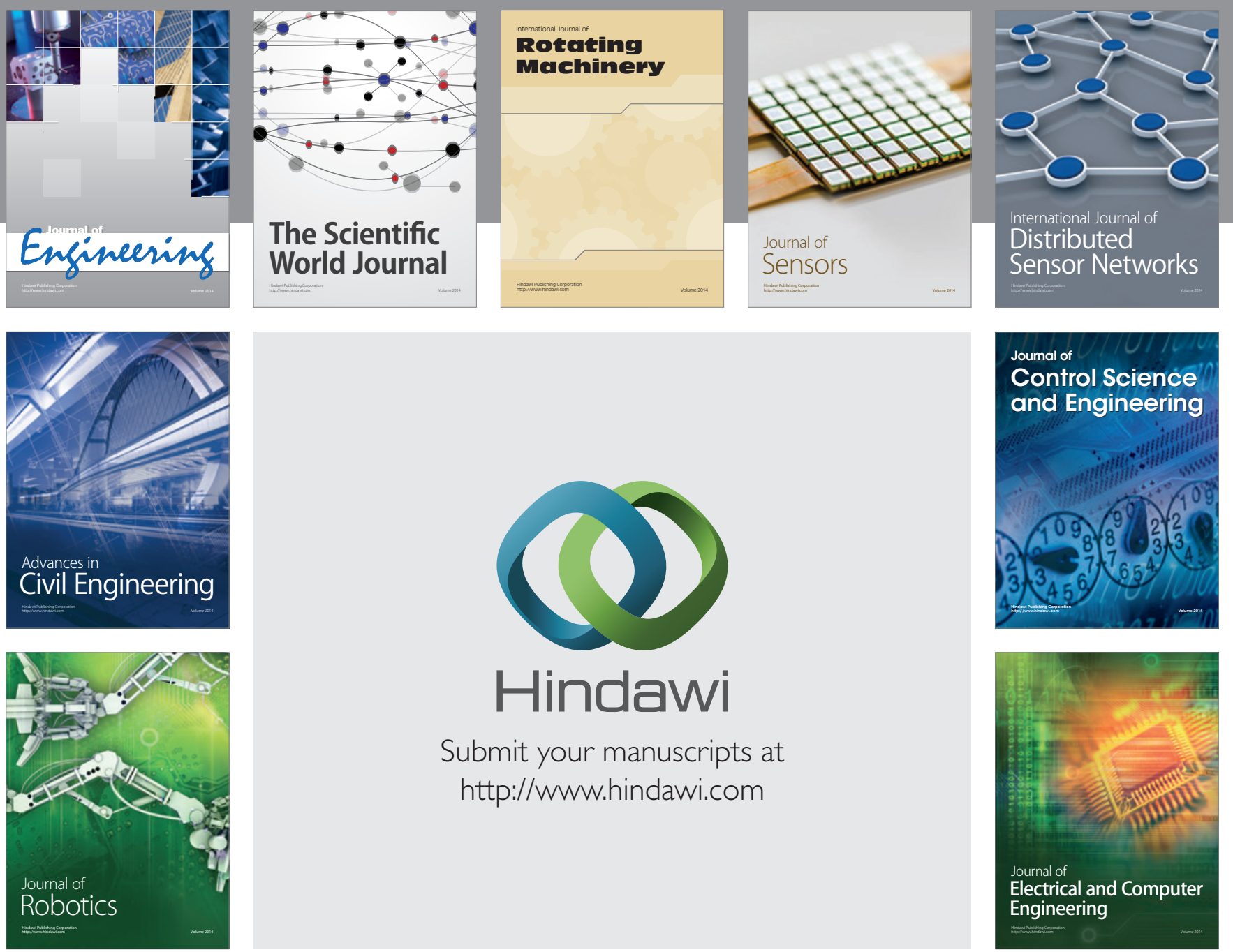

Submit your manuscripts at

http://www.hindawi.com
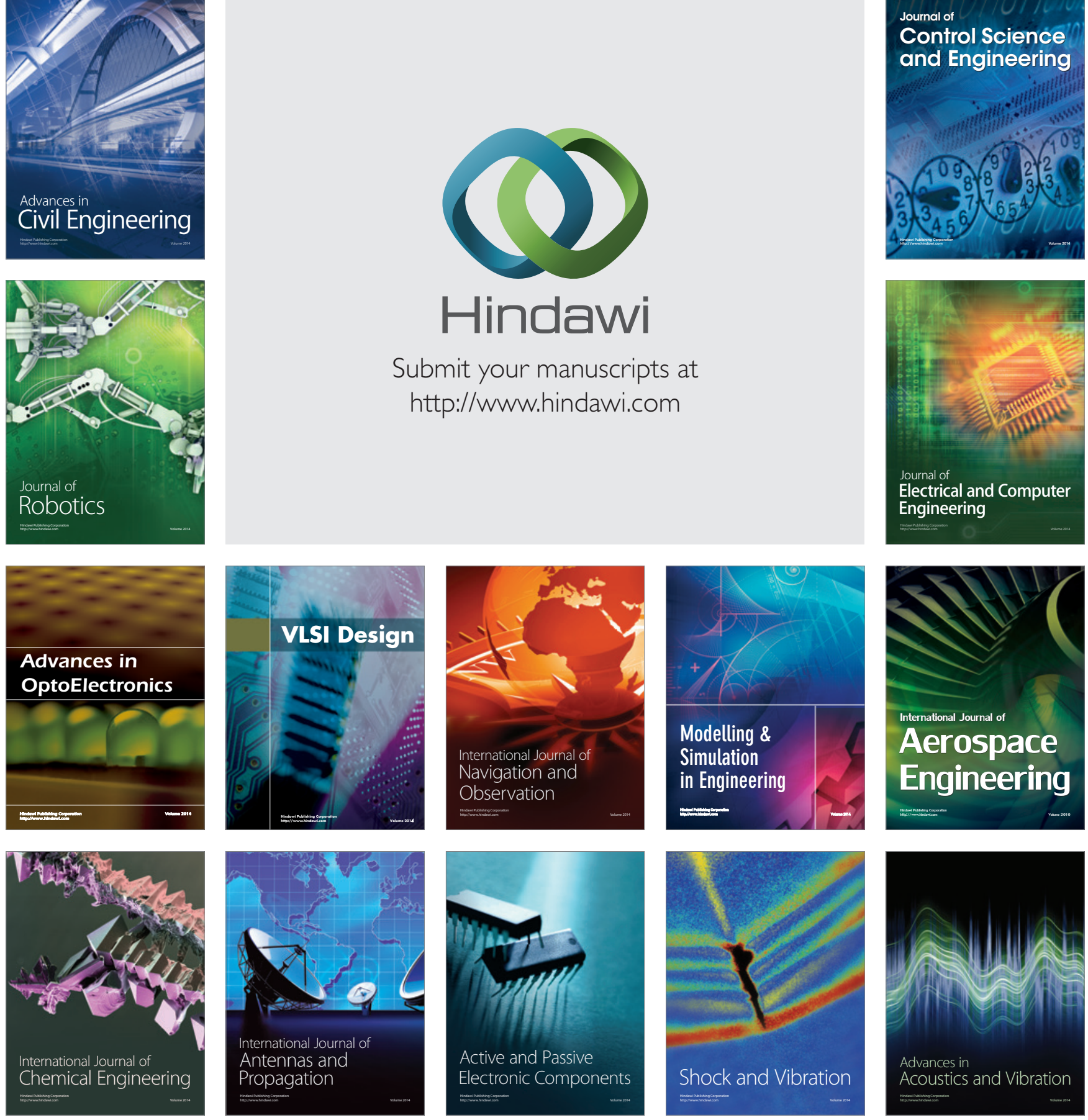